\title{
BECOMING INDIVIDUALS TOGETHER: SOCIALISATION IN THE JAPANESE PRESCHOOL
}

\author{
Rachael Burke
}

\begin{abstract}
Early childhood educators and parents in New Zealand commonly express the hope that young children become independent, creative individuals. In contrast, Japanese preschools work towards a harmonious group of children whose views and behaviour are mirrored by their classmates. Dominated by lengthy periods of free play with little disciplinary action by teachers, classes as large as forty introduce children to 'life in the group' (shüdan seikatsu) and to essential Japanese social values. This approach is often at odds with stereotypical images New Zealanders may have of Asian children as academically driven from an early age. As New Zealand institutions face increasing numbers of Asian children entering the early childhood sector, this paper examines the ideology and practice of shüdan seikatsu socialisation methods prevalent in Japanese preschools in the hope of stimulating critical reflection by New Zealand educators on their own methods and goals.
\end{abstract}

\section{INTRODUCTION}

Visiting any urban early childhood education centre in New Zealand today, one is struck by the plethora of children of various ethnicities that make up the modern roll. In areas such as Auckland many of those children have Asian ${ }^{1}$ origins and are likely to speak a language other than English with their family members (Statistics New Zealand 2008). Figures collected by the New Zealand Ministry of Education show that Asian children represent the biggest leap in the number of early childhood enrolments, with numbers up by 21.2 percent in the four years between 2002 and 2006. ${ }^{2}$ Although the overall number of Asian children attending early childhood centres is still small compared to European and Maori children, ${ }^{3}$ the New Zealand Asian population is predicted to double over the next two decades, eventually exceeding Maori (Bedford and Ho 2008: 23). It is safe to assume these rising enrolments will eventually have a 
cultural impact on domestic early childhood pedagogy and practice.

In the New Zealand context, it is common for parents and educators to use terms such as independent, creative and empowered when discussing hopes for their children. This position is supported by the national early childhood curriculum, Te Whaariki (Ministry of Education 2006) that also stresses the importance of well-being, belonging and family input as part of its bi-cultural plan. As New Zealand institutions face increasing numbers of Asian children entering the early childhood sector, how do the expectations of these children and their parents resonate with those of their New Zealand peers? While New Zealand educators may promote consistency of behaviour and discipline methods between the centre and the home, are these expectations realistic for families from other cultures? ${ }^{4}$

Participants in the New Zealand education system frequently express stereotypical views that Asian families prize academic-oriented activities above playing in the sandpit, a sentiment supported by the New Zealand media (Black 2007; Claridge 2005; Swain 1995; Samson 1992). In some instances, children from culturally diverse countries such as Japan, China and Korea are labelled as a homogenous group by early childhood centre members who claim 'they all look the same.' On the other hand, many centres are actively embracing cultural diversity in the form of classroom displays of national costumes, international greetings and social events like international lunches'. While these efforts are most definitely appreciated by the immigrant population how much do centre staff, parents and children really know about education methods in the early childhood centres of Asian countries?

While a broad, cross-cultural view of Asian early childhood pedagogies would undoubtedly also be beneficial, the following analysis focuses exclusively on the country of Japan. Based on fieldwork carried out in rural Japanese kindergartens and day-care centres in $2006^{5}$ this paper discusses the ideology and practice of shüdan seikatsu socialisation methods prevalent in Japanese preschools. ${ }^{6}$ An examination of Japanese practice may be a useful means of stimulating reflection and dialogue regarding theory and methods within the New Zealand early childhood sector.

THE POSITION OF THE PRESCHOOL IN JAPANESE AND NEW ZEALAND CONTEXTS

Anthropological discourse points to attendance at some form of preschool as an important first step for young Japanese towards mastering essential social 
behaviour and values (Hendry 1986; Lewis 1995; Peak 1991; Holloway 2000). This sentiment appears to be shared by Japanese parents, judging by the high percentage of children enrolled at kindergarten and day-care even though it is not compulsory to attend. On a national level, the number of children enrolled at officially recognised centres has dramatically risen in the post-war years, from 1.138 million attending kindergarten and 830,000 in day-care in 1965, to 1.76 million kindergarteners and 2.48 million day-care attendees in 2003 (Japan Statistical Yearbook 2006: 699). The number of day-care facilities has steadily risen as kindergarten enrolments decline, reflecting the changing need for child-care services for working women (Japan Statistical Yearbook 2006: 699).

This trend is being replicated in the New Zealand context for similar reasons with a 51 percent increase in the number of children attending early childhood education and care centres in the years 1999 to 2006 . While national kindergarten rolls have remained static at around 45,000 the number of children attending day-care centres in 2006 has jumped to $86,000,2.8$ times more enrolments than in 1990 (Ministry of Education 2008). The early childhood sector has also diversified and expanded rapidly in recent years with parents able to choose from sessional kindergartens, childcare, parent-lead playcentres, Maori and Pacific language immersion centres, coordinated family day-care and the correspondence school early childhood service (Anning, Cullen and Fleer 2004:10).

In both Japan and New Zealand it is clear that early childhood education occupies a prominent place in the world of a young child. Holloway (2000:2) notes:

The preschool is a core institution in Japan, viewed as providing essential experiences that enable young children to obtain social and intellectual skills needed to function successfully in Japanese society. As such, it serves a conservative cultural function - both preserving and transmitting Japanese social values to the younger generation.

However, in a land where mothers are widely recognised as the best caregivers for children (Fujita 1989), the rise of the preschool is fairly recent. It is worth briefly outlining the historical origins of the Japanese yöchien (kindergarten) and hoikuen (day-care centre) before examining the home environment, which supports the goal of child socialisation but in ways that may differ to the expectations of New Zealand educators. 
While the declining birth rate has seen the Japanese kindergarten (yōchien) and the day-care centre (hoikuen) increasingly resemble each other, the historical origins and aims of these two institutions were distinctly different. Founded in 1876 , the first national kindergarten followed the theories of educationalist Froebel and was seen by Meiji Japan (1868-1912) as a way of introducing Western ideals (Shoji 1983). The most recent revision of kindergarten guidelines by the Ministry of Education in 1989 reflected social change in the post-war years, seeking 'to bring up generous people who can cope with changes in the $21^{\text {st }}$ century' (Ishigaki 1992: 117). Despite Western perceptions (Cummings 1989), the aims of preschool have never promoted academic ability, but have evolved to reflect the prevailing social conditions. ${ }^{7}$

In contrast, the roots of the modern Japanese day-care facility can be seen in nurseries founded in Kyoto in 1875 to serve the needs of women labouring in factories. The level of care at these nurseries was minimal, 'so that women could work, reflecting a different purpose from the education-oriented kindergartens' (Shwalb et al 1992: 332). At the end of World War II the Japanese government (under the American occupation) passed the School Education Law in 1947 that placed yochien under the control of the Ministry of Education (Monbusho $)^{8}$ and the Child Welfare Law, which made hoikuen part of the Ministry of Health and Welfare (Köseisho) (Boocock 1989: 45). For many scholars, this remains the fundamental difference between the two forms of preschool in Japan, with the yōchien seen as preparing children for school, while the hoikuen serves the needs of the poor and working women (Shwalb et al 1992:336, Smith 1994: 69, Boocock 1989:46, Hendry 1986:126).

In 1989 and 1990, following reports by international media which focused on the image of Japanese children as young as two heading off to cram school (People Weekly 1984), the Ministry of Education issued new guidelines which stated preschools should view spontaneous play as their primary aim, and refrain from academic instruction (Ishigaki 1991). While this was a radical departure from earlier authoritarian structures and practices, some centres had difficulty putting 'free play' into practice, which resulted in chaotic scenes of fighting and disorder (Davies and Kasama 2004:97). Ten years later, some institutions were still grappling with the means to apply this new concept, leaving teachers confused and unsure that the quality of their programs had improved as a result of the guidelines implementation (Holloway 2000: 184-6). 
While some scholars write that as far back as the Edo period theorists were recognising the educational value of play (Ishigaki 1991; Shoji 1983), others argue that the behaviour represented at these preschools is relatively recent, and such institutions represent cultural values accepted by modern Japanese society (Holloway 2000:3; Davies and Kasama 2004:76). It is clear that most modern Japanese preschools now accept free play as an essential part of the early childhood experience. Astute principals realise that play is not just about having fun, but that since playground interactions are 'deeply embedded in children's collective, interpretive reproduction of their culture, socialization is not only a matter of individual adaptation and internalization, but a process of appropriation, reinvention, and reproduction' (Corsaro 1985:1).

While the modern Japanese preschool can be seen as a product of historical and contemporary social forces and ideologies, can the same be said for its young attendees? Does the behaviour of Japanese preschoolers reflect a continuum of their home environment as fostered by Te Whaariki (Ministry of Education 1996:42) with New Zealand children? The answer to these questions lies in an examination of Japanese child-rearing methods.

THE PATH TO PRESCHOOL

Hendry (1986) identifies the home, the neighbourhood and the preschool as crucial early 'arenas and agents of socialisation' for young children as they proceed towards 'becoming Japanese'. For mother and child, this journey begins in child-rearing patterns in which the Japanese mother views the baby as an extension of herself, limiting unnecessary verbal communication in favour of more vitally important physical contact (Schooler 1996:145-146). The Japanese mother also avoids separation from her baby and generally feeds on demand to reinforce the baby's emotional dependence on her (Befu 1971:151-157).

Implicit in the cultural ideology of the mother and child is the belief that the construction of this relationship is fundamental not only to the family, but builds aspects of character seen as uniquely Japanese. Deterioration of the mother-child relationship has even been linked to childhood illness and general social malaise (Jolivet 1997: 101). According to psychiatrist Takeo Doi, the concept of amae is central to this belief. Amae is difficult to translate accurately into English, with the closest meaning being 'dependency'. He argues that 'amae is a key concept for the understanding not only of the psychological makeup of the individual Japanese but of the structure of Japanese society as a whole' (Doi 1973: 28). Amae is seen as essential for babies and young children, allowing them to feel secure in their mother's love. Even as they grow into 
adults, this dependency is encouraged, in contrast to New Zealand, where children are praised for becoming independent. ${ }^{9}$

An analysis of the ways in which Japanese and American scholars studied childhood concluded that the major difference lay in how maturity was viewed in terms of becoming independent (Hara and Wagatsuma 1974). While Americans associated maturity with 'becoming an independent individual', the Japanese scholars felt that 'a mature person knows when, how, and on whom to be dependent or not dependent' (Hara and Minagawa 1996:11). Indeed, someone who tries to be too independent can be seen as having failed to understand how to amaeru. In the New Zealand context, scholars have pointed out that the national curriculum, Te Whaariki, presents the child as competent and capable, but primarily as an individual learner (Alvestad and Duncan 2006:41) despite the concerns of some critics (Ritchie 2003).

The early years at home are also when children learn to distinguish behaviour appropriate for the setting. For Japanese society, an essential element of socialisation is the classification of $u c h i$ and soto, which roughly translate as 'inside' and 'outside'. This may be a physical distinction, such as within or outside of the home, but also extends to family members as opposed to the outside community, including members of wider groups, such as the neighbourhood, kindergarten, school or workplace, as opposed to others beyond those groups. For young Japanese, the acknowledgement of this distinction begins by repeating their mother's ritualised greetings, which are given both by those leaving or entering the house, and those seeing off or receiving a guest or a family member home, and even small children will quickly learn to utter them at the appropriate time (Hendry 1995: 43-44).

The home, or $u c h i$, is the private, intimate arena in which one can relax, let all of one's feelings show, and expect indulgence and sympathy from other members of the family. Within the uchi a healthy amount of self-indulgence, regressive behaviour, and mild aggression are not only cheerfully tolerated but also encouraged as an indication of intimacy and trust. However, in the soto, or outside world, one must learn to assume a genial and cooperative public persona, in which individual feelings and desires must be subjugated to the harmony and activities of the group (Peak 1991:7).

As the child learns to discriminate between these two social spheres, they also come to realise that $u c h i$ is a place where amae will be accepted and even praised by mother, as opposed to soto where amae behaviour is inappropriate and discouraged (Azuma 1986:8). In contrast to the relative freedom of the 
uchi environment, when interacting in the soto world, individuals are expected to show enryo, which translates roughly as 'restraint' or 'holding back'. Doi suggests that enryo is, in fact, an inverted form of amae, where one must not assume too much of another's good will (amaeru) or else run the risk of being thought rude and consequently disliked (Doi 1973:39).

To be able to function smoothly in Japanese society as an adult, it is essential that children learn to distinguish between the $u c h i$ and soto, and adjust their behaviour accordingly. While Japanese mothers promote amae behaviour within the family home, they expect children to learn to display enryo towards peers, neighbours and members of the wider community. For most Japanese children, the first time they encounter this expectation is when they enter preschool (Peak 1991:16).

In contrast to the New Zealand context, where educators ask parents to encourage continuity between home and kindergarten or day-care (Ministry of Education 1996; Jones 2006), the Japanese preschool has a different focus. Peach (1994:3) argues that:

because the cultures within and outside the home are so different, and because it is culturally inappropriate for mothers to train children in behavior and attitudes appropriate for the outside world, the Japanese have come to believe it is the responsibility of the school to socialize children to the cooperative and self-effacing norms of what the Japanese call 'shüdan seikatsu' or 'life in a group'. So what does 'life in a group' look like?

THE PRESCHOOL ENVIRONMENT IN PRACTICE

Many researchers found their first visits to Japanese preschools to exhibit unexpectedly high levels of noise and supposedly chaotic scenes (Peak 1991, Lewis 1995). These images were in direct contrast to the stereotypical views being then proffered in the West, of Japanese children quietly and obediently being drilled in their lessons by an authoritarian instructor. Other reports portrayed individual Japanese youngsters as lost in a homogeneous sea of matching uniforms, hats and backpacks (Smith 1994).

The Japanese centre has an explicitly stated aim of socialising children to life in the shüdan environment, where the building of strong, cooperative groups is paramount. In many Western cultures, however, the emphasis seems to be on children gaining independence (Garbarino and Abramowitz 1992:56). While 
the New Zealand early childhood curriculum does not explicitly emphasise an individualistic approach, it does suggest that children initiate and direct their own learning through play and exploration (Ministry of Education 1996: 82). Chan (2006:35) points out that 'these learning outcomes become part of the teaching ideology of most New Zealand teachers, who value and promote selfhelp and independent exploration skills in children'. Alternatively it may also be argued that Te Whaariki's goal of contribution is not unlike that of shüdan seikatsu: 'Through interactions with others, children learn to take another's point of view, to empathise with others, to ask for help, to see themselves as a help for others, and to discuss or explain their ideas to adults to other children' (Ministry of Education 1996: 64).

In contrast, Japanese society views appropriate dependence as an essential skill for youngsters to develop (Doi 1973). Child-rearing practices, parental involvement and the education system see appropriate dependency as supporting the process of wakaraseru ('getting the child to understand') as opposed to more authoritarian methods in order to achieve a sunao (compliant, cooperative) child. 'A child who is sunao hasn't yielded his personal autonomy for the sake of cooperation: cooperation doesn't imply giving up the self, as it may in the West, but in fact implies that working with others is the appropriate setting for expressing and enhancing the self' (LeVine and White 2003:180). In this way, while young children learn to suppress their own desires within the early childhood environment, they are also learning interdependency skills that will be valuable for their own personal development and success. ${ }^{10}$

How are these goals implemented and achieved by the centres? An analysis of the daily routines of the yōchien and hoikuen visited is a useful way to identify strategies employed by teachers and administrators.

Children arrive from 8 am onwards, stowing their bags in cubbyholes and exchanging their outdoor shoes for indoor sneakers. Pinned to their clothes is a colourful name badge which links them to other members of their class even during the boisterous free play period. At assembly the children organise themselves into class lines and offer a ritualised greeting promising to play together, be happy and make good friends.

After completing a morning exercise routine, the children file out to their classrooms, where the teacher plays the piano to signify everyone should sit down. Musical cues are used extensively in Japanese preschools, to signify both the beginning and end of activities, and to change the pace or mood of the classroom. All early childhood educators are required to be able to play the piano, 
and each classroom contains a piano, or at the very least, a portable keyboard for this purpose (Tobin, Wu and Davidson 1989:56).

Whole-hearted participation in activities is seen as a particularly valued quality, and the calling of the roll requires a clear answer from children. As LeVine and White (2003:180) note, 'the style in which one does one's work indicates affective commitment and is considered almost as important as the product of the performance.' Mastering the ritualised greetings (aisatsu) that mark social interactions in Japan is the most commonly cited object of training (shitsuke) at the preschool level (Hendry 1986:73).

The greetings are usually led by duty monitors (tōban) summoned to the front of the class. Each child takes on this role at least once a term according to a rotating flip chart on the wall, yet many children can barely disguise their excitement and pride as they make their way to the front. To signify their special status for the day, handmade stuffed felt animals are pinned to their clothing, and the class uses honorific language to address the tōban as they bow and ask for their classmates' protection and help. As Lewis (1995:106) notes, 'the tōban system seemed to capitalize on children's natural interests for attention, prestige, and a chance to lead others and seemed to give children a chance to experience the pleasure - and headaches - of responsibility. The jobs expected of tōban vary, but might include leading the class in greetings or songs as described above, distributing work materials, deciding when the class was quiet enough to begin an activity, and ensuring all students were correctly dressed at home time. The tōban system serves an important function: to allow even the shyest child the chance to be a leader, and to create empathy for authority while simultaneously developing a 'good-child' (ii ko) identity. ${ }^{11}$

For day-care children mid-morning signifies a return to the free play of earlier. For kindergarten students, this is when they begin a teacher-directed activity with other class members. During my fieldwork, students were practising for the upcoming kindergarten concert (happyōkai). While New Zealand parents appreciate any effort that children make to publicly perform in the early childhood arena, Japanese parents have high expectations for a polished performance from their offspring. As a result, Japanese kindergarten and day-care concerts are full-scale perfected productions. To achieve these results, children rehearse relentlessly in the weeks before the concert. The class is assembled by the teacher who bows and informs the children that they are about to 'begin work' (shigoto o hajimarimasu). They also respond by bowing, chanting in unison 'onegai shimasu', a ritualistic means of requesting a favour from someone. The children try to master their instruments, identical sets of kenban 
hämonika; a kind of keyboard with a flexible tube into which the children blow while pressing the keys. The teacher demonstrates the musical notes, the children copy and practice the tune until the teacher rings a bell for everyone to stop. It is quite a complex task, but the children doggedly repeat the notes until signalled to halt. Someone is still playing. The teacher comments, 'We all need to do it together or we can't make beautiful music - we need to make sure our friends have mastered the piece. Some of us are still learning the notes, so please let's try hard not to blow our instruments even if we have mastered it ourselves'. She signals for them to commence practice again, and moves about the class, listening to each child individually, offering instructions and correcting their fingers over the keys. At the end, the teacher asks for a show of hands from those who have perfected the piece. About half the class raises their hands. The teacher says 'Some hands are still down, so those of you who put hands up, would you mind taking some time (during free play) to show the others how to play the music (oshiete itadakimasen $\mathrm{ka}$ )? Thank you'. The language she has chosen for this request is formal and humble, not usually the kind directed at children from her superior position. Over the lunch break, several of the more able children instruct their grateful classmates in the art of the kenban hämonika.

Day-care centres begin preparing for lunch about 11.30 am when the teacher asks the children to first lay out their futons for the nap which will follow mealtime. The children work together to carry tables out to the hall, then unpack their individual chopstick sets and lay out the container of rice they have brought from home before heading across to wet their own wash cloths under the taps. The tōban are kept busy retrieving the food trolleys from the kitchen and placing bowls of food on the table. While a full-time cook prepares the food, families are expected to contribute by supplying cooked rice each day for their child.

Once all the food is out on their table and the children seated, the group pauses to give thanks for the meal by simultaneously uttering 'itadakimasu', an important mealtime greeting. Children are strongly encouraged not to leave any food behind, and to eat quietly and neatly to show gratitude for the meal they have been given. Manners surrounding mealtimes is cited by teachers as of paramount importance in socialising children, one of the few issues they feel might warrant disciplinary action (Hendry 1986:76).

In Japanese preschools, teachers are expected to remain seated with students at lunch times, consuming the same hot meal supplied at the day-care, or eating from their homemade lunchboxes (bentō) just like their students in the kinder- 
garten. This not only allows staff to remind boisterous children to eat quietly, it means that they can monitor and influence what the children are consuming, and at the same time act as a model for good table manners. In the preschool environment, it is the responsibility of the teacher to ensure children have a healthy diet, a responsibility they take very seriously. This role is actualised in the form of the renraku cho, a notebook taken from home to preschool each day and into which teachers write detailed notes about each child's daily diet, bowel motions, demeanour and ability to play with classmates.

At $12.15 \mathrm{pm}$, the day-care staff begin preparing for naptime. Students are sent to clean their teeth and put on their pyjamas with the younger children receiving assistance with buttons and zips from older members. The children each have home-sewn bedding bags, which contain a pillowcase and towels to use as sheets and blankets. The futons are pushed together and the children spread their towels out over their sleeping space. The teacher pulls the blackout curtains, turns off the light and lies down between them, patting their backs and softly humming a lullaby. Within thirty minutes the children are all asleep and even the teachers sometimes nod off for a while. Teachers maintain that sleeping together in a group helps to make the children feel relaxed and safe, speeding their journey towards slumber.

While it may seem that co-sleeping replicates the amae setting of the home, Ben-Ari argues instead that this shared physical experience helps children to internalise the distinctions between the family and the outside world:

Naptime is one form through which day-care centres effect the transfer of strong relations from the family dyad to the peer group. There is a transfer here - or an addition - of the warmth, the comfortableness, and the commitment and involvement of children in the dyad at home to the wider group (Ben-Ari 1997:52).

Ben-Ari suggests that practices such as naptime function to instil particular traits and qualities connected with 'being Japanese'.

In contrast at kindergarten, the children do not take a nap, as their official finishing time is $2.00 \mathrm{pm}$. After devouring the contents of their lunchboxes, the children are free to play until $1.20 \mathrm{pm}$, when it is time to tidy up. While some children play independently many youngsters cluster in small groups making mud pies and daisy chains or examining insects. Children who wish to join in the play, first watch the others, and then step up to the group asking 'irete?' (may I join your group of friends?), receiving the unanimous reply ' $i-i-y o$ ' (yes, 
go ahead). This scene marks an important social interaction that takes place all over playgrounds in Japan: a formal request for entry into the group, which facilitates harmonious group relations. Following this procedure guarantees a smooth path into play in progress, as it is extremely rare for children to refuse a request (Elwood 2003). While the language of this exchange may become more sophisticated as young Japanese enter adulthood, the sentiment remains the same.

At $1.30 \mathrm{pm}$ the kindergarten teachers call the children inside to collect their belongings, tidy the classroom and conduct the farewell rituals. Thirty minutes later the kindergarten bus arrives to collect about half the students, while a cluster of mothers wait in the foyer for their children to be released. A small number of children will remain behind in after school care, watching videos and playing, until their parents finish work. Even in this supposedly informal space, teachers remain watchful of the children's behaviour, observing how they are interacting with their peers. Ben-Ari (2002:116) notes that most teachers are required to fill in a chart for each child recording information such as physical, linguistic and motor development, but also in the section on social relations (shakaisei), [teachers] record how the kids play together in their group, whether they cooperate, whether they keep to the rules and if they can behave like everyone else. In this way, teachers can regularly monitor how well their pupils are managing to adapt themselves to the preschool environment.

By $3.00 \mathrm{pm}$ it is snack-time at the day-care, when the teacher sits at the piano and begins playing a calming melody, which acts as a musical cue for the children to sit down in their class groups and wait for the duty monitor to distribute the snacks. While the day-care centre usually provides refreshments, there is also the opportunity for children to share souvenir (omiyage) chocolate or candy they have brought back from trips beyond the preschool arena. The recipients of these unexpected presents are the immediate classmates of the child, and even if children from other classes may look longingly at the sweets they do not ask to share them. The giving of omiyage will come to have multiple meanings in the adult world, but even as preschoolers children learn that a family trip marks them as representing their preschool $u c h i$ group in an external environment, and the gifts they bring back, however trivial, symbolise a positive effort on the behalf of the whole group (Graburn 1983:58).

While the late afternoon 'goodbye' song signifies time to go home for most children, for some students this is when they begin extra-curricular lessons for which their parents pay additional fees, often to specialist teachers contracted for this purpose. At elite private day cares, the children already have a busy 
schedule with instruction in dance, swimming, athletics, English, piano, skiing, and painting. After school classes capitalise on those skills, either offering more intensive opportunities to practice, such as one-to-one English lessons, or to develop extra skills like computing. Many of these classes have been instigated at the request of upwardly mobile parents seeking a competitive edge for their offspring in Japan's academically stratified society.

Although this description has been fused from ethnographic data collected at five academically and ideologically divergent preschools, pedagogical strategies compatible with the goals of shïdan seikatsu are common to all. Tobin (1987:547) identifies these as:

(1) delegating authority to children, (2) intervening less quickly in children's fights and arguments, (3) having lower expectations for children's noise level and comportment, (4) using more musical cues and less verbal ones, (5) organizing more highly structured, largegroup daily activities such as taisō (morning group exercise), (6) using a method of choral recitation for answering teacher's questions rather than calling on individuals, and (7) making more use of peergroup approval and opprobrium and less of the teacher's positive and negative reactions to influence children's behavior'.

There are some similarities to the New Zealand early childhood education context but visitors to a Japanese kindergarten might initially jump to the same conclusion as Smith (1994: 43): 'Japanese allow preschoolers to form groups and create their own sources of group cohesion with a minimum of adult interference. It seems to matter little to Japanese preschool teachers whether the resulting groups resemble a flock of screaming banshees or if individual members misbehave'. Although first impressions may support Smith's views Japanese educators have their own culturally constructed approach to organising and disciplining children that contrasts with methods utilised in New Zealand early childhood education centres.

\section{METHODS OF SOCIAL CONTROL}

Many anthropologists (Hendry 1986a; Lewis 1995; Peak 1991; Tobin, Wu and Davidson 1989) look at a schedule dominated by free play, little apparent disciplinary action by teachers, and consequently deafening noise levels as a defining feature of the Japanese preschool. Instead cultural assumptions and differences define what constitutes problematic behaviour and appropriate methods of discipline (Smith 1994; Lanham and Garrick 1996, Sato 1998). While New 
Zealand educators might find hyperactivity and hitting to be particularly troubling (Ministry of Education 1996:52), Japanese teachers see excessive reliance on the teacher and non-participation in-group activities as undesirable behaviour (Peak 1989).

Children who run about the Japanese early childhood centre, shrieking and yelling, are not regarded as mondai ji (problem children) but are seen as expressing energy and enthusiasm conducive with being a child. This behaviour is considered by many teachers to contribute to strength of character in later years. Teachers cheerfully tolerate high levels of noise and activity, and avoid direct use of their authority to discipline individual children, instead ignoring inappropriate behaviour or encouraging the class to govern their own actions.

Japanese teachers, who will generally ignore fights, intervening only if the incident has gone on for a protracted time, also treat hitting as relatively inconsequential. Even then, teachers are not motivated to identify and punish the aggressor, but seek to re-establish harmony and elicit an apology from both parties. 'Japanese teachers do not consider hitting a 'crime' or a demonstration of anti-social tendencies. Rather, it indicates social immaturity and frustration at an inability to verbalize one's feelings' (Peak 1989:108). Students with behaviour or academic problems are viewed as those most in need of opportunities to socialise in order to take responsibility for them and to learn to exercise self-control (Sato 1998:128).

While American and Chinese teachers taking part in a cross-cultural study were shocked by the levels of violence and unruly behaviour recorded between children in a Japanese day-care centre, the Japanese principal felt that fighting, especially among boys, served an important developmental purpose:

If there were no fights among four-year-old children, that would be a real problem. We don't encourage children to fight, but children need to fight when they are young if they are to develop into complete human beings... When children are preschool age they naturally fight if given the chance, and it is by fighting and experiencing what it feels like to hit someone and hurt them and to be hit and be hurt that they learn to control this urge to fight, that they learn the dangers of fighting and get it out of their system (Tobin, Wu and Davidson 1989:33). 
Japanese teachers see children who provoke fights as giving other children a valuable opportunity to practice resolving conflicts themselves, and to assist in mediating disagreements between their classmates. Teachers may even employ more direct strategies in order to provoke conflict, such as putting out fewer toys or crayons than there are children, forcing them to learn to cooperate and share the limited resources (Tobin, Wu and Davidson 1989).

While hitting and hyperactivity are tolerated in most Japanese classrooms, staff do not support a child's over-reliance on the teacher or refusal to participate in group activities. In their observations of preschool children in Japan and the United States, Lanham and Garrick (1996:104), found the way the teacher related to the class the striking difference between the two settings. While American children sought attention and praise from the teacher, the Japanese teacher limited her participation in children's interactions, leaving it up to class members to assist those who required help.

For children who have spent their early years being completely cared for at home by their mothers, the transition to preschool life can be a rude shock. Rather than having mother's help in dressing, feeding and even wiping bottoms, at kindergarten children are expected to gradually master these tasks themselves. Teachers do not chastise an uncooperative child, but maintain their distance by busying themselves with the rest of the class, while acknowledging the request but encouraging a reticent child to continue trying by themselves (jibun de gambatte). 'Establishing in children a self-reliant (jiritsu) and 'independent' (jishu) attitude is fundamental to creating a distinction between the amae-based world of the home and the group life of the preschool. Making a sincere effort to perform one's own role and master proper personal habits of daily life is one of the most important functions of shüdan seikatsu. Overreliance on the teacher is in direct opposition to this' (Peak 1989:115). Tobin, $\mathrm{Wu}$ and Davidson (1989:38) have suggested that large classes of up to forty children also prevent the teacher from spending inordinate amounts of time with one child, instead encouraging individuals to undertake tasks themselves or consult with their peers for help.

Along with over-reliance on the teacher, Peak (1989) regards non-participation in group behaviour as a serious offence within the Japanese early childhood sphere. She notes that this issue is a concern to educators, not just because group activities form the basis of preschool life, but also because children's non-participation threatens teachers who are themselves well-socialised products of the group-oriented culture of Japan. Lewis (1995:74-100) also recognises that the fixed small groups of the preschool class function to manage 
the children more effectively, while also providing emotional and academic support. In some centres teachers will actively 'match' personalities, so that the more able sit beside those who are struggling, or shy children are near sociable classmates. If children remain reluctant to participate, Japanese teachers take a 'wait and see' approach, often allowing children to roam about the grounds freely until they decide to join their classmates. Rather than seeing a child as deliberately misbehaving, teachers generally believe that such children 'don't yet understand the fun of being together with others' (minna to issho ni iru tanoshisa ga wakaranai) (Peak 1989:116).

At the crux of the Japanese concept of discipline is belief in the 'good child' identity, which assumes that all children are basically good and should be given ample opportunities, both within the family and outside it, to reinforce this positive self-image (Lewis 1995, Singleton 1991, White and LeVine 1986, Yamamura 1986). Teachers are reluctant to label children as 'naughty' or 'disobedient' but maintain that misbehaving children lack sufficient understanding of appropriate and inappropriate behaviour.

Holloway (2000:156) suggests that the Japanese concept of discipline has its roots in Shinto beliefs, where children may have inadvertently acquired some tsumi (impurities), which can easily be eliminated by the appropriate ritual. With the blame externalised away from the perpetrator, Western attempts to 'correct' a child's behaviour are seen as futile by Japanese parents and teachers. 'Japanese rely on excuses that acknowledge young children's bad behaviour as undesirable or wrong, but deny personal responsibility for conduct; Americans apply justifications that admit personal responsibility but deny the act's wrongness' (Smith 1994: 40). Japanese early childhood educators work on getting children to understand why certain rules are essential to life in a group, rather than trying to make them comply through force or coercion (Lewis 1995: 133-4).

This belief is typified by an incident that occurred during my fieldwork. In the four-year-old class at a private kindergarten, the teacher had discovered a trio of boys had destroyed another child's origami display. She picked up the crumpled cranes from the floor, but waited silently until all the children were sitting down and their chatter had finally subsided. Holding up the crumpled paper, the teacher inquired, 'What do you think has happened to our beautiful cranes?' Various children called out 'it's been squashed,' 'someone has ripped it', 'it's all broken now'. The teacher calmly nodded, while looking sadly at the cranes, and commented, 'I wonder how the cranes are feeling now...' Responses such as 'sad', 'upset' and 'lonely' come from the class. The 
teacher agreed, 'Right, they must be feeling that way. So, how we can stop this from happening again?' The children eventually came to a consensus that the display was there for looking at, so 'we have to help our friends not to touch things.' The teacher nodded encouragingly, and proceeded to lead the children in the 'good morning' song. While it was clear who the perpetrators were, no one moved to identify or punish them. The problem had been 'owned' by the group, who proceeded to solve it.

The teacher also called upon the children's feelings through personification of the paper cranes. Lewis (1995: 136) notes:

When teachers appealed on behalf of the 'feelings' of objects, or people, they were asking for children's help - and in a way that masked the conflict between the desires of child and teacher. In contrast, a direct request would have underlined this conflict.

While we can see that Japanese teachers use a number of strategies to manage behaviour in the early childhood environment, peer control is most often used as a means of resolving conflicts and problems among children. Although this is seen as a desirable outcome within the overall aim of shüdan seikatsu, it can also have negative consequences. Lewis (1995:140-2) has questioned whether teachers who allow children to continue physical fighting maybe condoning violence as a means of problem solving.

While the current debate surrounding the rising levels of violence in Japanese schools continues (Kanetsuna, Smith and Morita 2006, Nesdale and Naito 2005, Yoneyama and Naito 2003), some scholars have suggested that bullying (ijime) in Japanese educational institutes has long been a problem that is sanctified by teachers, parents and classmates who pretend indifference to the victims of violence (Murakami 1991:196). At the same time, reports of incidents of abuse in early childhood centres have also risen substantially, especially in unregulated institutions and 'baby hotels' (Goodman 2002). The issue of bullying within the early childhood sector warrants further investigation within the research surrounding shüdan seikatsu methodology.

\section{CONCLUSION}

In summing up it is also necessary to debunk a few myths held about Japanese early childhood education. Firstly, while yōchien and hoikuen grew out of differing social and historical needs, neither were established with the sole intent to offer scholarly instruction to preschoolers. While academic stratification 
within modern Japanese society has given rise to private day-cares which teach literacy and numeracy skills, this move has been predominantly motivated by parental demands rather than governmental policy.

The path to preschool begins at home where Japanese child-rearing practices promote interdependence between family members (amae) to give children a strong emotional base. While mothers lovingly indulge their children in the home (uchi) environment, preschool teachers see their role as preparing children for life in Japanese society (the soto world) through practical application of shüdan seikatsu socialisation methodology.

Contrary to stereotypes of group socialisation methods as producing 'compliant robots', shüdan seikatsu ideology does not aim to quash individuality but recognises each child's capabilities and weaknesses as contributing to the strength of the whole class group. Preschool teachers seek to encourage each child's individual character while simultaneously socialising children towards 'life in the group. These two concepts are not seen as opposing, but complementary as Sato (1998:121) explains: 'Individual development is both bound and enhanced by membership in mutual learning communities, and those communities, in turn, are strengthened by increased individual capacities; they complement one another towards reciprocal growth.'

Educators, who devote considerable time to ritualising class activities such as the morning greetings, calling of the roll and mealtime etiquette, foster a cooperative group spirit. These rituals reinforce the correct way to perform essential Japanese social interactions as well as giving every child an opportunity to take on the role of class leader (tōban).

Ethnographic research conducted by scholars such as Boocock (1989) and Kotloff (1993) shows how Japanese preschools foster cooperative group spirit without sacrificing individuality and spontaneous self-expression. They also identify training methods for Japanese teachers as placing emphasis on observation of children's behaviour, and acquisition of practical skills over abstract theories of child development and pedagogy. Such studies, which have been identified as valuable for American preschools, may also be useful for New Zealand early childhood educators seeking an international approach to deal with increasingly diverse centres. Ramsey (1982) suggests that developing a sense of community in the classroom can facilitate multicultural awareness and acceptance among children. 
Despite the widespread belief that the academic success of Asian children is due to strict schooling from an early age, Japanese preschools take a non-authoritarian approach that relies on peer control to facilitate conflict resolution and to build mutually rewarding relationships. Children are encouraged to cooperate with their classmates and those who refuse to participate in group activities or try to dominate the teacher's time are gently ignored until they choose to rejoin the class in an appropriate manner.

While the number of Japanese children attending New Zealand early childhood education centres may still only be minimal at this time, an examination of 'outsiders' pedagogical and socialisation methods provides a useful lens through which to view one's own community. It is hoped this discussion might also provide some understanding towards cultural differences and stimulate dialogue regarding what constitutes appropriate and inappropriate behaviour in the New Zealand early childhood sector.

\section{NOTES}

1 The New Zealand Census of Population and Dwellings (2006) defines 'Asian' as people from twenty-seven countries in the geographical region extending from Pakistan in the West to Japan in the East (Bedford and Ho 2008:2).

2 Data collected about children on the regular rolls of early childhood education (ECE) providers reveals that the number of Asian children has increased 21.2 percent in the past four years. In contrast, enrolments of European children have increased 4.1 percent while the figures show a 6.8 percent increase for Maori and a drop of 0.2 percent for Pasifika children (New Zealand Ministry of Education 2008).

3 Asian students comprise 5.8 percent of New Zealand's total ECE enrolments. As of July 2006, European enrolments were 67.3 percent, Maori 19 percent, Pasifika 6.2 percent and other groups 1.6 percent (New Zealand Ministry of Education 2008).

4 Te Whaariki (Ministry of Education 1996:65) notes that 'Children's cultural values, customs and traditions from home should be nurtured and preserved to enable children to participate successfully in the early childhood setting and in their community.'

5 Fieldwork was conducted using participant-observation methodology at five Hokkaido centres during September - October 2006. Before this, I had lived in 
Hokkaido for almost six years, when my three children attended preschool and I was employed as a kindergarten teacher. Interviews were conducted in Japanese and all translations are my own. For a detailed explanation of this project's research questions and methodology see Burke (2007).

6 Some New Zealand educators may object to the use of the term 'preschool' on the grounds that this is seen to privilege the school orientation of early childhood education. Similarly, the terms 'classroom' and 'teacher' can be problematic in the New Zealand context (Siraj-Blatchford 2004: 137). However, 'preschool' is familiar to international educators and the term is frequently used when discussing early childhood education as part of comparative research (Alvestad and Duncan 2006). In Japan, the 'teacher' must be addressed as such (sensei) and children are grouped into 'classes', a deliberate strategy used to foster cooperation and group membership.

7 For a comprehensive history of early childhood pedagogic concepts in Japanese preschools, see the excellent article by Ishigaki (1991) which discusses prominent theorists and how their views influenced Japanese educational trends.

8 Monbusho has since been renamed Monbukagakusho (Ministry of Education, Culture, Sports, Science and Technology).

9 In New Zealand, independence is cited as a key area of development for children in the national curriculum statement for the early childhood sector, Te Whaariki (Ministry of Education 1996: 21). Independence as a goal of early schooling has also been discussed by New Zealand academics (Higgins 2000; Wylie and Smith 1993). In terms of children's age (five to six years) the first two years of New Zealand primary school equates to approximately the last eighteen months of preschool in Japan (depending on when the child's birthday falls).

10 This approach can also be seen in the New Zealand context in the philosophies followed by Te Kohanga Reo (Maori language nests) where an extended familybased approach encourages interdependence between children and adults within a group culture (Nyland and Rockel 2007:80).

11 For a discussion of the ii ko ('good child') identity, see White and LeVine (1986). 


\section{REFERENCES}

Alvestad, M. and J. Duncan 2006 “"The Value is Enormous - it's Priceless I Think!”: New Zealand Preschool Teachers' Understandings of the Early Childhood Curriculum in New Zealand - A Comparative Perspective', International Journal of Early Childhood, 38 (1):31-45.

Anning, A., Cullen, J. and M. Fleer 2004 'Research Contexts Across Cultures', in A. Anning, J. Cullen and M. Fleer (eds) Early Childhood Education: Society and Culture, London: Sage Publications:1-15.

Azuma, H. 1986 'Why Study Child Development in Japan?', in H. Stevenson, H. Azuma, and K. Hakuta (eds) Child Development and Education in Japan, New York: W.H. Freeman:3-12.

Bedford, R. and E. Ho 2008 Asians in New Zealand: Implications of a Changing Demography, Hamilton: Population Studies Centre, University of Waikato.

Befu, H. 1971 Japan: An Anthropological Introduction, San Francisco: Chandler Publishing.

Ben-Ari, E. 1997 Body Projects in Japanese Childcare: Culture, Organization and Emotions in a Preschool, Richmond: Curzon Press.

Ben-Ari, E. 2002 'State Standardisation and 'Normal' Children: An Anthropological Study of a Preschool', in R. Goodman (ed.) Family and Social Policy in Japan: Anthropological Approaches, Cambridge: Cambridge University Press: $111-130$.

Black, J. 2007 'Greater Expectations; Going for it; Hard Data; Techno Timebomb', New Zealand Listener, 9 June, 209 (3500):14-23.

Boocock, S.S. 1989 'Controlled Diversity: An Overview of the Japanese Preschool System', Journal of Japanese Studies 15 (1): 41-65.

Burke, R. 2007 Changing Times for Young Minds: Declining Class Size and Shūdan Seikatsu Ideology in Hokkaido Preschools, Unpublished Masters thesis, Auckland: Massey University.

Chan, A. 2006 'The Teachers Said My Child is Different', The First Years: Nga Tau Tuatahi: New Zealand Journal of Infant and Toddler Education, 8 (1):34-38. 
Claridge, A. 2005 'Secrets of Success', The Press, 3 December 2005: D5.

Corsaro, W.A. 1985 Friendship and Peer Culture in the Early Years, Norwood: Ablex.

Cummings, W. K. 1989 'The American Perception of Japanese Education', Comparative Education 25 (3), Special Number (12): 293-302.

Davies, B. and H. Kasama 2004 Gender in Japanese Preschools: Frogs and Snails and Feminist Tales in Japan, Cresskill, NJ: Hampton Press.

Doi, T. 1973 The Anatomy of Dependency, Tokyo: Kodansha.

Elwood, K. 2003 'Cultural Conundrums: It's a Jungle (gym) Out There', The Daily Yomiuri, 11 March: 13.

Fujita, M. 1989 ' "It's all Mother's Fault”: Childcare and the Socialization of Working Mothers in Japan', Journal of Japanese Studies, 15 (1): 67-91.

Garbarino, J. and R.H. Abramowitz 1992 'Sociocultural Risk and Opportunity', in J. Garbarino (ed) Children and Families in the Social Environment, $2^{\text {nd }} \mathrm{ed}$, New York: Aldine de Gruyter:35-70.

Goodman, R. 2002 'Child Abuse in Japan: 'Discovery' and the Development of Policy', in R. Goodman (ed.) Family and Social Policy in Japan: Anthropological Approaches, Cambridge: Cambridge University Press: 131-155

Graburn, N. 1983 To Pray, Pay and Play: The Cultural Structure of Japanese Domestic Tourism, Aix-en-Provence: Centre des Hautes Etudes Touristiques.

Hara, H. and M. Minagawa 1996 'From Productive Dependents to Precious Guests: Historical Changes in Japanese Children', in D.W. Shwalb and B.J. Shwalb (eds) Japanese Childrearing: Two Generations of Scholarship, New York: Guildford Press: 9-30.

Hara, H. and H. Wagatsuma 1974 Shitsuke, Tokyo: Kobundo.

Hendry, J. 1986 Becoming Japanese: The World of the Preschool Child, Honolulu: University of Hawaii Press.

Hendry, J. 1995 Understanding Japanese Society, $2^{\text {nd }}$ ed, London: Routledge. 
Higgins, J. 2000 'Independence as a Goal of Education', in L Bird and W. Drewery (eds) Human Development in Aotearoa: A Journey Through Life, Auckland: McGraw-Hill: 134-135.

Holloway, S.D. 2000 Contested Childhood: Diversity and Change in Japanese Preschools, New York: Routledge.

Ishigaki, E.H. 1991 'The Historical Stream of Early Childhood Pedagogic Concepts in Japan', Early Child Development and Care, 75:121-59.

Ishigaki, E.H. 1992 'The Preparation of Early Childhood Teachers in Japan, Part I: What is the Goal of Early Childhood Care and Education in Japan?', Early Child Development and Care, 78:111-138.

Japan Statistical Year Book [Nihon Tōkei Nenkan]. 2006 Tokyo: Nihon Tōkei Kyōkai.

Jolivet, M. 1997 Japan: The Childless society? The Crisis of Motherhood. London: Routledge.

Jones, C. 2006 'Continuity of Learning', SET Research Information for Teachers, 2: 28-31.

Kanetsuna, T., P. K. Smith and Y. Morita 2006 'Coping with Bullying at School: Children's Recommended Strategies and Attitudes to School-Based Interventions in England and Japan', Aggressive Behaviour 36 (5):570-580.

Kotloff, L.J. 1993 'Fostering Group Spirit and Individuality - Examples from a Japanese Preschool, Young Children 48 (3):17-23.

Lanham, B.B. and R. J. Garrick 1996 'Adult to Child in Japan: Interaction and Relations', in D.W. Shwalb and B.J. Shwalb (eds) Japanese Childrearing: Two Generations of Scholarship, New York: Guildford Press: 97-124.

LeVine, R.A. and M. I. White 2003 'Educational Mobilization: The Case of Japan', in R. LeVine (ed.) Childhood Socialization: Comparative Studies of Parenting, Learning and Educational Change, Hong Kong: University of Hong Kong: $159-185$.

Lewis, C.C. 1995 Educating Hearts and Minds: Reflections on Japanese Preschool and Elementary Education, Cambridge, New York: Cambridge University Press. 
Ministry of Education 1996 Te Whaariki: He Whariki Matauranga mo nga Mokopuna o Aotearoa: Early Childhood Curriculum, Wellington: Learning Media.

Ministry of Education 2008 'Participation in early childhood education', www. educationcounts.govt.nz/indicators/student_participation/early_childhood_education_/participation_in_early_childhood_education

Murakami, Y. 1991 'Bullies in the Classroom', in B. Finkelstein, A.E. Imamura and J.J. Tobin (eds) Transcending Stereotypes: Discovering Japanese Culture and Education, Yarmouth: Intercultural Press:190-196.

Nesdale, D. and A. Naito 2005 'Individualism-Collectivism and the Attitudes to School Bullying of Japanese and Australian Students', Journal of CrossCultural Psychology, 36 (5):537-556.

Nyland, B. and J. Rockel 2007 'Infant-Toddler Care and Education in Australia and Aotearoa/New Zealand: In Search of Status', in L. Keesing-Styles and H. Hedges (eds) Theorising Early Childhood Practice: Emerging Dialogues, Castle Hill, Nsw: Pademelon Press: 71-95.

Peach, M. 1994 'The Nonacademic Curriculum of the Japanese Preschool', Childhood Education, 71 (1):9-15.

Peak, L. 1989 'Learning to Become Part of the Group: The Japanese Child's Transition to Preschool Life', Journal of Japanese Studies, 15 (1): 93-123.

Peak, L. 1991 Learning to Go to School in Japan: The Transition From Home to Preschool Life, Berkeley: University of California Press.

People Weekly 1984 'In Japan a Tot's First Taste of Schooling is 'Examination Hell', November (22): 46.

Ramsay, P.C. 1982 'Multicultural Education in Early Childhood', Young Children, $37(2): 13-25$.

Ritchie, J. 2003 'Te Whariki as a Potential Lever for Bicultural Development, in J. Nutall (ed) Weaving Te Whariki: Aotearoa New Zealand's Early Childhood Curriculum Document in Theory and Practice, Wellington: NZCER:79-109.

Samson, A. 1992 'Family Figures Large in Asian Student Success', Dominion Sunday Times, 23 March: 14 . 
Sato, N. 1998 'Honoring the Individual', in T. Rohlen and G. LeTendre (eds) Teaching and Learning in Japan, Cambridge: Cambridge University Press:119153 .

Schooler, C. 1996 'William Caudill and the Reproduction of Culture: Infant, Child, and Maternal Behavior in Japan and the United States', in D.W. Shwalb and B.J. Shwalb (eds) Japanese Childrearing: Two Generations of Scholarship, New York: Guildford Press: 139-163.

Shoji, M. 1983 'Early Childhood Education in Japan', in G. Lall and M. Bernard (eds), Comparative Early Childhood Education, Chicago: Charles C. Thomas: $48-62$.

Shwalb, D.W., B.J Shwalb, S. Sukemune and S. Tatsumoto 1992 'Japanese Nonmaternal Child Care: Past, Present, and Future', in M.E. Lamb, K.J. Sternberg, C. Hwang and A.G. Broberg (eds) Child care in Context: Cross-cultural Perspectives, Hillsdale, NJ: Lawrence Erlbaum:331-353.

Singleton, J. 1991 'The Spirit of Gambaru', in B. Finkelstein, A.E. Imamura, and J.J. Tobin (eds), Transcending Stereotypes: Discovering Japanese Culture and Education, Yarmouth, Maine: Intercultural Press: 119-125.

Siraj-Blatchford, I. 2004 'Quality Teaching in the Early Years', in A. Anning, J. Cullen and M. Fleer (eds), Early Childhood Education: Society and Culture, London: Sage Publications: 137-148.

Smith, H. 1994 The Myth of Japanese Homogeneity: Social-Ecological Diversity in education and socialization, Commack, N.Y.: Nova Science.

Statistics New Zealand 2008 'Birthplace', www.stats_govt.nz/cmsapp/templates/ system/migration.

Swain, P. 1995 'Why Asians do Well at School', Dominion, 22 September: 7.

Tobin, J.J. 1987 Class Size and Student Teacher Ratios in the Japanese Preschool, Comparative Education Review, 31 (4):533-549.

Tobin, J.J., Wu, D.Y.H., and D.H. Davidson 1989 Preschool in Three Cultures: Japan, China and the United States, New Haven: Yale University Press. 
Tobin, J.J., D.Y.H Wu and D.H Davidson 1990 'Class Size and Student Teacher Ratios in the Japanese Preschool', in J.J. Shields (ed.) Japanese Schooling: Patterns of Socialization, Equality and Political Control, University Park: The Pennsylvania State University Press: 59-72.

White, M.I. and R.A. LeVine, R.A. 1986 'What is an Ii Ko (Good Child)?', in H. Stevenson, H. Azuma, and K. Hakuta (eds) Child Development and Education in Japan, New York: W.H. Freeman: 55-62.

Wylie, C. and L. Smith 1993 Learning to Learn: Children's Progress Through the First Years at School, Wellington: New Zealand Council for Educational Research.

Yamamura, Y. 1986 'The Child in Japanese Society' in H. Stevenson, H. Azuma, and K. Hakuta (eds), Child Development and Education in Japan, New York: W.H. Freeman: $28-38$.

Yoneyama, S. and A. Naito. 2003 'Problems With the Paradigm: The School as a Factor in Understanding Bullying (With Special Reference to Japan)', British Journal of Sociology of Education, 24 (3):315-330. 